\title{
ИНЖЕНЕРНАЯ ПЕДАГОГИКА
}

\section{Институциональное обеспечение непрерывного инженерного образования}

Будзинская Ольга Владимировна - канд. экон. наук, доцент. E-mail: budzinskaya@bk.ru Шейнбаум Виктор Соломонович - канд. техн. наук, проф. E-mail:shvs@gubkin.ru Российский государственный университет нефти и газа (НИУ) им. И.М. Губкина Москва, Россия

Адрес: 119991, г. Москва, Аенинский проспект, 65

Аннотачия. В статье поднимается вопрос о необходимости фиксачии В профессиональньх стандартах - основньх нормативных документах в сфере квалификачии - требований, касаюшихся обязательности непрерывного развития профессиональных компетениий работников, в том числе через институт дополнительного профессионального образования. Предложены Варианты Внесения этих требований без изменения установленного формата профстандартов. Отстаивается опережаюшая роль исследовательских и проектньх университетов - системообразующих структур в индустрии знании - в формировании квалификачионных требований по новым направлениям и видам профессиональной деятельности, аргументируется необходимость разработки и реализачии программ профрессиональной переподготовки специалистов до того, как они офичиально обретут соответствуюший статус и для них будут разработаны и утверждены профессиональные стандарть.

Ключевые слова: непрерьвное профессиональное образование, профессиональные стандарть, цифровизачия, дополнительное профессиональное образование, отраслевые советь по профессиональньм квалификачиям

Аля иитирования: Будзинская О.В., Шейнбаум В.С. Институциональное обеспечение непрерывного инженерного образования // Высшее образование в России. 2018. Т. 27. № 10. C. 30-46.

DOI: https://doi.org/10.31992/0869-3617-2018-27-10-30-46

\section{Введение}

Происходящий на наших глазах переход к новому экономическому укладу, обозначаемый многими специалистами по истории науки и техники как четвёртая промышленная революция, включает и утверждение новой образовательной парадигмы: «образование не на всю жизнь, а через всю жизнь» [1]. Аанная парадигма и предложенные концепции непрерывного образования находят своё практическое воплощение в бурном развитии дополнительного образования, различных его видов и форм, образовательных технологий и новых организованностей.

Сразу уточним, что в контексте обсуждаемых в статье проблем различия в понятиях «образование» (как результат, процесс, ин- ститут), «самообразование», «подготовка специалистов», «обучение», на которые постоянно обращают внимание методологи и философы [2], представляются непринципиальными. Будем исходить из того, что обучение, как оно обычно трактуется, в том числе и самообучение, есть основной способ получения образования, приобретения и развития профессиональных компетенций, подготовки людей к профессиональной деятельности, и далее сфокусируемся на нём.

Концепцию непрерывного образования всегда отличала избыточная понятийно-терминологическая множественность ${ }^{1}$ [3]. За

${ }^{1}$ См.: Владиславлев А.П. Непрерывное образование: проблемы и перспективы. М.: Молодая 
рубежом для обозначения этого феномена используются различные термины: «непрерывное» (permanent), «продолженное» (continuing), «возобновляемое» (recurrent), «пожизненное» (lifelong) образование. В том, что эти идеи сегодня активно переводятся в операциональную плоскость в большинстве экономически развитых стран мира, существенную роль сыграло, как известно, ЮНЕСКО [4], которое сумело объединить экспертов этих стран и наладить продуктивный обмен идеями и национальным опытом.

В марте 2000 г. в Аиссабоне на саммите стран Европейского союза был принят Меморандум непрерывного образования ${ }^{2}$ [5], в котором обозначены две его главные цели: 1) активная гражданская позиция и 2) конкурентоспособность на рынке труда. Включённость в гражданское общество практически невозможна без успешной про-

гвардия, 1979. 175 с.; Филиппов Ф.Р. Социальные аспекты непрерывного образования // Советская педагогика. 1982. №6. С. 34-41; Вербицкий А.A., Нечаељ Н.Н., Юрисов В.В. Концептуальные основы перехода к непрерывному образованию. М.: ИзА-во НИИ ВШ, 1989. 40 с.; Концепция непрерывного образования // Народное образование. 1989. № 10. С. 3-12; Концепция профессионального непрерывного образования // Профессиональное образование. 1990. № 4. С. 65-78; Перспективы развития системы непрерывного образования / Под ред. Б.С. Гершунского. М.: Педагогика, 1990. 221 с.; Байденко В.И. Стандарты в непрерывном образовании: концептуальные, теоретические и методологические проблемы. М.: Исследовательский центр качества подготовки специалистов, 1999. 296 с.; Ильин Г.А. От педагогической парадигмы к образовательной // Высшее образование в России. 2000. № 1. С. 64-69; Гребнев А.С. Образование: услуга или жизнь? М.: ИзА-во МААИ, 2005.90 с.; Шленов Ю.В., Мосичева И.А., Шестак В.П. Непрерывное образование в России // Высшее образование в России. 2005. №3. С. 3-10; Непрерывное образование в политическом и экономическом контекстах / Отв. ред. Г.А. Ключарев. М.: ИС РАН, 2008.

${ }^{2}$ Меморандум непрерывного образования Европейского союза. URL: http://znanie.org.docs/ memorandum.html фессиональной карьеры, поскольку она составляет фундамент личной независимости, самоуважения, социальной защищённости и благополучия, а значит, определяет качество жизни. Занятость понимается как ценность, как необходимый фактор и параметр развития гражданского общества и благосостояния стран Европейского союза в целом. А успех на рынке труда и участие в общественных процессах требуют наличия актуальных компетенций и квалификаций и, соответственно, доступа к современным знаниям, что как раз и обеспечивается институтами непрерывного образования. Эти цели, разумеется, разделяет и Россия.

\section{Проблемная ситуация}

При формировании рыночных отношений в прежних плановых механизмах обеспечения потребностей экономики в специалистах вполне естественно возникли разрывы и дисбалансы. Нехватка рабочих кадров, переизбыток экономистов и юристов, резкое сокращение численности аспирантов и, как следствие, снижение инженерного и научнопедагогического потенциала - всё это общеизвестно. На этом фоне всё громче голоса тех, кто видит корень зла в попытках интегрироваться в Европейское образовательное пространство, введении ЕГЭ, упразднении системы распределения выпускников вузов, переходе высшей школы на подготовку специалистов по системе «бакалавр - магистр», и всё слабее тех, кто оправдывает подключение России к Болонскому процессу. Аля инженерного сообщества чрезвычайно актуальной стала тема ранней - начиная с дошкольного возраста - профориентации молодого поколения и последующего непрерывного технического образования. Подробный системный анализ данной проблематики вместе с развернутой программой стыковки всех звеньев этой цепи представлен в [6].

В настоящей статье мы рассматриваем ту составляющую непрерывного образования, которая касается преимущественно инже- 
неров и относится ко всему периоду их профессиональной деятельности. Эта составляющая в нашей стране нередко трактуется как дополнительное профессиональное образование (АПО). Таков, как утверждается в [7], традиционный взгляд на непрерывное образование как на «по сути, компенсаторное, дополнительное образование, часть “конечного” образования (т.е. “образования на всю жизнь”)». Конечно же, в узком понимании этот термин уже изжил себя. Но мы не станем предлагать его модификацию и не последуем за академиком А.А. Вербицким, предложившим в [8] существенно обновить понятийный аппарат теории образования. Говоря о АПО, мы будем подразумевать профессиональное образование специалистов, которое становится непрерывным и нуждается в институциональном обеспечении. В эссе «Накануне схода лавины. Высшее образование и грядущая революция» в подтверждение того, что обучение персонала становится постоянным фактором производственного процесса, приводится такой факт: «на заводах BMW, например, процесс сборки автомобилей настолько автоматизирован, что сотрудники, число которых сильно сократили, до половины рабочего времени посвящают учёбе. Работа и учёба становятся неразделимыми - не это ли имеется в виду, когда говорят об экономике знаний или об обучающемся обществе?» [9].

Ао 2013 г. дополнительное профессиональное образование было под патронажем государства, с принятием в декабре 2012 г. Федерального закона «Об образовании в Российской Федерации» государство из этой сферы (за исключением дополнительного образования детей и сегмента, связанного с подготовкой государственных служащих) практически ушло. А что касается его непрерывности, то она была и остаётся весьма условной. В том смысле, что 17 или даже 72 узаконенных часа повышения квалификации один раз в три, а то и в пять лет - это не то, что следует понимать под непрерывным образованием.
Сегодня АПО - один из видов коммерческих услуг, попросту говоря, бизнес, оно по преимуществу платное, круг субъектов этой деятельности существенно шире и пестрее традиционных образовательных учреждений. Отменены дипломы о дополнительном образовании государственного образца, государственная аккредитация программ дополнительного образования, не предусмотрены и какие-либо государственные образовательные стандарты для дополнительного образования. Ни Минобрнауки России, ни Рособрнадзор не проводит экспертиз

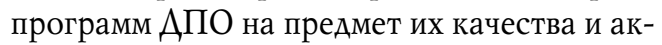
туальности. Предполагается, что в системе АПО рынок, то есть экономические законы спроса и предложения всё расставят по местам автоматически. А функции регулятора в этой системе могут быть возложены на отраслевые советы по профессиональным квалификациям (СПК) - постоянно действующие органы создаваемой в стране национальной системы профессиональных квалификаций, призванные обеспечивать формирование и развитие систем профессиональных квалификаций по определённым видам профессиональной деятельности. Уже есть свидетельства, что СПК действительно берутся выполнять эти функции, но пока они лишь нащупывают рычаги, необходимые для регулирования системы АПО. К примеру, в СПК нефтегазового комплекса (СПК НГК) нашло поддержку предложение допускать к профессиональной переподготовке по инженерным направлениям через механизм профессионально-общественной аккредитации только те образовательные учреждения, которые аккредитованы государством и реализуют соответствующие образовательные программы высшего или среднего профессионального образования.

\section{Кейс}

Ниже мы обсудим это предложение, но вначале рассмотрим один кейс, позволяющий выявить обстоятельства, препятству- 
ющие «проникновению» идей непрерывного образования «в массы». В июле 2016 г. в Градостроительный кодекс (далее ГрК) имеющий статус Федерального закона, внесены поправки, согласно которым специалистами-строителями, имеющими право быть включёнными в национальный реестр специалистов в области строительства, являются исключительно лица с базовым строительным образованием (часть 6 статьи 55.5). Цитируем:

«6. Сведения о физическом личе, указанном в части 1 настоящей статьи, включаются... В начиональный реестр спечиалистов в области строительства (далее также - национальные реестры спечиалистов) на основании заявления такого лииа при условии его соответствия следуюшим минимальньм требованиям:

1) наличие высшего образования по профессии, специальности или направлению подготовки в области строительства;

2) наличие стажа работь соответственно в организачиях, выполняюших инженерные изыскания, осуществляюших подготовку проектной документачии, строительство, реконструкиию, капитальный ремонт объектов капитального строительства на инженерных должностах не менее чем три года;

3) наличие общего трудового стажа по профрессии, спещиальности или направлению подготовки в области строительства не менее чем деслть лет;

4) повышение квалификачии специалиста по направлению подготовки В области строительства не реже одного раза в пать лет;

5) наличие разрешения на работу (для иностранных граждан)».

Приказом Минстроя России от 6 апреля 2017 г. № 668 эти положения подтверждены; кроме того, утверждён включающий 285 позиций перечень направлений подготовки, специальностей в области строи-

\footnotetext{
${ }^{3}$ Градостроительный кодекс РФ, введён Федеральным законом от 03.07.2016 № 372-Ф3.
}

тельства, получение высшего образования по которым необходимо для специалистов по организации инженерных изысканий, специалистов по организации архитектурно-строительного проектирования, специалистов по организации строительства. Обратим внимание, что в указанном перечне нет направлений подготовки специалистов в ряде ведущих университетов России: МФТИ, МГУ им. М.В. Аомоносова, МИФИ, Томском политехническом университете (физика, техническая физика, прикладная математика и физика, прикладная математика и информатика, системный анализ и управление, информатика и вычислительная техника, фундаментальная информатика и информационные технологии, программная инженерия). Этот факт не казался бы странным, если бы в указанном перечне не было таких специальностей, как многоканальные телекоммуникационные системы, приборостроение, радиофизика и электроника, электроника и наноэлектроника...

Как следует из ГрК, профессиональная переподготовка персонала, занятого в отечественном строительстве, не предусмотрена как способ приобретения статуса специалиста по организации строительства, имеющего право быть включённым в соответствующий национальный реестр. Овладение в относительно короткие сроки новыми профессиями, новыми компетенциями, переучивание носителей утративших актуальность компетенций и тем самым снятие социальной напряженности на рынке труда в принципе невозможно без дополнительного образования в форме профессиональной переподготовки. Это доказано опытом всех промышленно развитых стран. И то, что градостроительный кодекс не допускает для главных инженеров проектов (ГИПов) получение строительных компетенций через профессиональную переподготовку, но разрешает им повышать квалификацию всего лишь один раз в пять лет (!) - это по нынешним временам нонсенс. Получается, что в век цифровизации и междисциплинарных технологий отечественный 
инженер-физик, инженер-программист, инженер-системотехник, по существу, лишён шансов быть допущенным к организации работ в строительстве в качестве ГИПа, даже если он через дополнительное образование в форме профессиональной переподготовки получит в лучшем строительном вузе страны предусмотренные профессиональным стандартом строительные компетенции и, проработав в строительстве 10 лет, успешно пройдет тестирование в профильном Центре оценки квалификаций (ЦОК), созданном во исполнение положений Федерального закона «О независимой оценке квалификации» № 238-ФЗ от 03.07.2016. Заметим: закона, принятого почти на год раньше упомянутого приказа Минстроя России, в котором результаты независимой оценки квалификации лиц, претендующих на включение в национальный реестр, сочтены не заслуживающими внимания.

Справедливости ради отметитим, что это упущение Минстроя России было впоследствии исправлено Квалификационным стандартом саморегулируемой организации СоюзСпецСтрой, в котором определено, что «соответствие специалиста по организации строительства требованиям, установленным Разделом 4 настоящего стандарта, должно подтверждаться путём проведения независимой оценки квалификации».

Из представленного кейса можно в предварительном порядке сделать, по меньшей мере, пять следующих выводов:

1. Модель непрерывного инженерного образования, предполагающая не только и не столько рихтовку компетенций, однажды полученных инженером в вузе, а постоянное в период его трудовой деятельности овладение новыми компетенциями, а при необходимости - и квалификациями, требуемыми Аля реализации передовых производственных технологий и технологий деятельности, пока ещё не вполне ингерентна для нашего бизнес-сообщества $[10 ; 11]$.

2. Аополнительное образование в форме профессиональной переподготовки по не аккредитованным государством програм- мам, т.е. не удостоверенное государственным дипломом, не внушает работодателям доверия.

3. В профессиональных стандартах нормативных документах, содержащих, согласно Трудовому кодексу, развёрнутую характеристику квалификаций, недостаточно чётко прописываются варианты образовательных траекторий (способов) получения квалификаций и компетенций, требуемых работнику для выполнения предписанных ему трудовых функций; если и предусматривается дополнительное профессиональное образование, в том числе в форме профессиональной переподготовки, то нередко без указания её профиля; не нормируется соответствующая темпам обновления технологий в отрасли периодичность повышения квалификации.

4. Законодательные акты, касающиеся требований к образованию работников, не должны противоречить соответствующим положениям профессиональных стандартов.

5. На государственном уровне, на уровне Национального совета по профессиональным квалификациям, Российского союза промышленников и предпринимателей (РСПП), Национального агентства развития квалификаций (НАРК), профессиональных союзов и ассоциаций пока никак не поощряется корпоративная политика непрерывного инженерного образования, отвечающая велениям времени, которая нацеливает менеджмент компаний и предприятий на технологизацию этого процесса.

\section{Профессиональные стандарты - важнейший инструмент \\ институционального обеспечения непрерывного образования}

Строго говоря, в парадигме «образования через всю жизнь» ничего нового нет: «Век живи - век учись» - говорят на Руси с незапамятных времен, а сама мысль восходит к римскому философу Сенеке. Зададимся вопросом, почему лишь в последние 30 лет эта поговорка обрела статус одного из смыслов 
государственной образовательной политики практически во всех экономически развитых странах мира.

Большинство экспертов в данном вопросе сходятся во мнении, что именно в этот период впервые в истории человечества цикл жизни реализуемых инноваций в технике и технологиях, включая технологии инженерной деятельности и менеджмента, реально сократился до уровня, существенно меньшего времени активной трудовой деятельности одного поколения. Констатация стремительного укорачивания времени жизни многих профессий стала уже общим местом [12; 13]. Вследствие убыстрения морального изнашивания, устаревания профессиональных компетенций, полученных выпускниками вузов и колледжей, фундамент сложившегося в обществе сакрального отношения $\mathrm{k}$ инженерному диплому как к непреходящей ценности стал терять свою прочность.

С осознанием этого факта различные социально-экономические институты приходят к пониманию, что в обеспечении посредством непрерывного обучения перманентной актуальности профессиональных компетенций персонала они являются, по меньшей мере, такими же стейкхолдерами, как и те, кому традиционно адресовалась упомянутая выше поговорка «Век учись». При этом необходимость непрерывного образования и переобучения перестала быть исключительно личной проблемой, а превращается в категорический императив для государства, стремящегося обеспечить в экономике доминирование индустрии знаний. Специалисты в области экономики труда дружно заговорили о возможности нормирования амортизационных отчислений на «ремонт компетенций», их восстановление по аналогии с отчислениями на восстановление основных фондов предприятий [14]. Опасения, сдерживавшие работодателей инвестировать в человеческий капитал по той причине, что, принося прибыль, этот ресурс, увы, не принадлежит им на правах собственности, что в любой момент самый ценный из сотрудников их компании может её покинуть, стали трансформироваться в понимание, что эта ценность должна, по крайней мере, адекватно оплачиваться.

Майским Президентским указом 2012 г. № 597 «O мероприятиях по реализации государственной сочиальной политики» был дан старт масштабному национальному проекту перехода страны на новую нормативную базу в сфере квалификаций, основополагающими документами которой являются Трудовой кодекс Российской Федерации, Национальная рамка квалификаций и Профессиональный стандарт. В макет профессиональных стандартов по мере их разработки и практического использования вносятся, как и должно быть, коррективы.

На наш взгляд, назрела необходимость отражения в профессиональньх стандартах в той или иной форме требований/рекомендачии, касаюшихся непреривного профессионального образования, в частности регулярности повышения квалификачии и его направленности. Профессиональный стандарт должен отражать предпочтительность для работодателя наличия сертификатов повышения квалификаций и независимой оценки полученных компетенций. Не случайно люди в своих резюме сообщают работодателям не только о своих академических степенях, но и последующих достижениях с акцентом на приобретении новых, актуальных для работодателей, востребованных ими компетенций. Нынешний макет профессионального стандарта, в принципе, позволяет разработчикам сделать это, используя позицию/строку в описании обобщённых трудовых функций «требования к образованию».

Хотелось бы, правда, отметить, что само понятие «повышение квалификации» в профессиональном стандарте звучит несколько двусмысленно: то ли это переход на следующий квалификационный уровень (ваши компетенции соответствовали, к примеру, 6-му квалификационному уровню, а в результате повышения квалификации, профпереподготовки стали соответствовать 7-му, и это 
вы можете подтвердить в Центре оценки квалификации), то ли это повышение вашей компетентности в рамках 6-го квалификационного уровня). Истоки этой двусмысленности - отсутствие в стране единого толкования понятия квалификации: в Трудовом кодексе - одно, в законе «Об образовании в Российской Федерации» - другое [15].

Ещё совсем недавно считалось само собой разумеющимся, что чем больше стаж работы и, следовательно, накопленный опыт, тем выше квалификация работника, тем он ценнее. Какую ни возьми статью, посвящённую прикладным аспектам теории человеческого капитала, читаешь, что человеческий капитал компании отличается от физического тем, что он не теряет своей стоимости в процессе использования. Более того, в процессе использования он якобы способен увеличивать свою стоимость. В первые годы использования человеческого капитала, полагают авторы этих статей, «за счёт физического взросления работника и за счёт накопления производственного опыта» его экономическая ценность не уменьшается, а возрастает [14]. Однако сегодня многие работодатели, прежде всего - владельцы и управляющие высокотехнологичными компаниями, так уже не думают. Они не понаслышке знают, что в настоящее время обесценивание интеллектуального потенциала работника, допустившего существенную паузу в развитии своих профессиональных компетенций посредством обучения, может происходить уже в первый год его трудовой деятельности.

Конечно же, с возрастом человек, как правило, становится мудрее. В зрелые годы люди избавляются от порывистости, импульсивности, их кругозор шире, они лучше оценивают риски, их решения становятся более взвешенными. Сплав жизненного опыта и молодости в инженерной деятельности всегда даёт желаемый синергийный эффект. Но чтобы это был именно сплав, чтобы в нём наличествовали прочные коммуникативные связи, необходим общий профессиональный язык, единый понятийный аппарат. Увы, сегодня старшее поколение работников по вполне объективным причинам частенько «не догоняет», как говорит нынешнее молодое поколение, призванное создавать в стране цифровую экономику.

Статьёй 195-1, включённой в декабре 2012 г. в Трудовой кодекс, согласно которой работник, не имеющий опыта работы, не может рассматриваться как обладающий квалификацией, подразумевается опыт, который необходим и позволяет работнику успешно решать стоящие перед ним задачи. Сегодня этот необходимый опыт отнюдь не всегда пропорционален стажу работы. Поэтому требования, подобные содержащемуся в ГрК, чтобы стаж работы в профессии, необходимый для включения работника в реестр специалистов-строителей, должен непременно быть не менее 10 лет, представляются несколько подозрительными. Практика свидетельствует, что успешно проектировать, организовывать строительство и строить здания, печатая их на 3D-принтере, могут сегодня специалисты и с меньшим стажем. Опыт работы, безусловно, является одной из важнейших характеристик квалификации и потому должен прописываться в профессиональных стандартах. Но коль скоро иной общепринятой его оценки, кроме как по стажу работы, пока нет, представляется целесообразным, чтобы в профессиональных стандартах допускалась возможность не директивного/жёсткого, а рекомендательного/мягкого характера записи, касающейся стажа работы. При этом, повторимся, в таком же рекомендательном ключе следовало бы в профессиональных стандартах (ПС) в описании обобщённых трудовых функций указывать (в строке «требования к образованию» периодичность повышения квалификации и профиль соответствующих программ).

Вышеназванная статья Трудового кодекса фактически конституировала полуфабрикатный статус выпускников инженерных вузов, о котором в течение последних 15 лет авторы писали не единожды [16]. Этот ста- 
тус является таковым вследствие того, что гарантировать своим студентам получение опыта практической работы вузы не могут, число принимаемых в вузы студентов не увязывается в условиях рыночной экономики с весьма ограниченным количеством практикантов, которых готовы принять хозяйствующие субъекты. И по причине отсутствия у большинства выпускников, в первую очередь у бакалавров, целого ряда практических компетенций, без которых они не могут с первого дня включиться в работу трудового коллектива, их обучение ( «доучивание») в крупных компаниях начинается сразу же после приёма их на работу, фактически в первый рабочий день.

Кроме того, высшая школа с её неповоротливой, крепко держащейся за традиции, исповедующей преемственность как наиглавнейшую ценность системой методического и организационного обеспечения образовательной деятельности, поражённой вирусом бюрократизации, в последние четверть века перестала, а возможно, уже и не способна в принципе в её нынешнем состоянии поспевать за лавинообразным потоком новых знаний и инноваций в инженерной деятельности.

\section{Непрерывное}

инженерно-педагогическое образование

Актуальность непрерывного образования распространяется на все сферы жизнедеятельности общества, в том числе и прежде всего на систему образования. В этой связи приведём выдержку из размещённого на сайте Национального агентства развития квалификаций - НАРК - описания новой модели повышения квалификации педагогических работников профессионального обучения, среднего профессионального образования и дополнительного профессионального образования (bc-nark.ru/training_center/novayamodel-povysheniya-kvalifikatsii/): «Сегодня всё более ярко проявляется тенденция подмены непрерывного профессионального образования формальным прохождением кур- сов повышения квалификации один раз в три года, а часто и это требование ФГОС СПО не выполняется. Так, по данным сводного отчета по форме № СПО-1 (2016 год) в целом по Российской Федерации за последние три года прошли повышение квалификации по профилю педагогической деятельности $58,32 \%$ мастеров производственного обучения (должно быть 100\%). Всего 17,9\% мастеров повышали квалификацию по профилю педагогической деятельности путём стажировки в профильных организациях, и всего 9,5\% прошли обучение в области информационно-коммуникационных технологий».

Острый дефицит рабочих кадров - операторов компьютеризированных технологических комплексов, специалистов среднего звена подвиг НАРК взять на себя организацию в масштабах страны повышения квалификации педагогических работников образовательных учреждений, осуществляющих образовательную деятельность по основным программам профессионального обучения, образовательным программам среднего профессионального образования и дополнительным профессиональным программам, на основе применения профессиональных стандартов, лучшего отечественного и международного опыта. Эта инициатива НАРК была поддержана и превратилась в поручение Правительства Российской Федерации от 29 сентября 2016 г., в соответствии с которым АНО «Национальное агентство развития квалификаций» с 1 января 2017 г. уполномочено осуществлять функции базового центра профессиональной подготовки, переподготовки и повышения квалификации рабочих кадров. И сегодня оно успешно это делает.

Что касается высшей школы, то само словосочетание «непрерывное образование профессорско-преподавательского состава» может кому-то резать слух, ибо по логике вещей сама суть научной и педагогической деятельности предполагает постоянное развитие и приумножение компетенций её субъектов. В вузах наличествуют подразделения 
(факультеты, центры, институты), организующие повышение квахификации ППС, и они, как правило, делают всё возможное по части освоения преподавательским корпусом современных информационных технологий, передового опыта в инженерной педагогике, в организации междисциплинарного обучения и т.д. Но расходы вузов по этому направлению из госбюджета финансируются только через субсидии и гранты и на конкурсной основе. Бизнес в повышении квалификации ППС оказывает помощь преимущественно ведущим университетам и спорадически, так что в итоге то, чем вузы России в своём бюджете располагают на эти цели, - это «почти ничего».

Потому-то в свои отчёты о повышении квалификации преподаватели вузов с согласия руководства вынуждены записывать не только целевые мероприятия развития конкретных профессиональных, в том числе педагогических, компетенций по заранее разработанным для каждого из них планам, а участие в различных, часто несолидных семинарах, круглых столах и т.п., подчас имеющих весьма отдалённое отношение $\mathrm{k}$ насущным потребностям вуза в данном направлении их деятельности. То есть, если назвать вещи своими именами, «что попало».

\section{«Хочешь заполучить}

\section{специалиста - вырасти его сам»}

В топливно-энергетическом комплексе корпоративная политика, основанная на этом принципе, уже проводится, что наглядно проявляется во внедрении его ведущими хозяйствующими субъектами - ПАО «Газпром», ПАО «Газпром Нефть», ПАО «НК “Роснефть" - компетентностного подхода в управлении персоналом. К примеру, в ПАО «НК “Роснефть” недавно утверждена программа развития персонала головных и специализированных институтов корпоративного научно-проектного комплекса (КНПК) на 2017-2018 гг. ${ }^{4}$, в которой в качестве ос-

\footnotetext{
${ }^{4}$ URL: https://www.rosneft.ru/Development/ knpk/Razvitie_personala_KNPK/
}

новных на ближайшую перспективу направлений работы в области развития персонала определены следующие:

- внедрение компетентностного подхода в развитие персонала ( 8 рамках реализачии компетентностного подхода в 2016 году были разработань матрича и профили профессионально-технических компетениии и оченочные материаль для персонала блоков «Геология и разработка» $u$ «Проектноизыскательские работь» КНПК бизнес-направления «Разведка и добыма»; запущен прочесс оченки персонала);

- разработка внутренних обучающих курсов и проведение обучения на базе прикладного учебного и инженерного центра (ПИУЦ) «Сапфир» (начата разработка вводного курса для персонала КНПК, курсов по Системе типового проектирования Компании, курсов для главньх инженеров проектов и других курсов).

При этом «непрерььность внутреннего обучения обеспечивается совместными усилиями сотрудников кадровых служб, руководителей подразделений и экспертов в различных профессиональных областях, что позволяет сохранить накопленный организационный потенциал, ускорить внедрение корпоративных стандартов, улучшить знание бизнес-процессов и межфункциональное взаимодействие» ${ }^{5}$.

В зависимости от целей, Аля достижения которых организуется обучение и развитие персонала ПАО «НК “Роснефть”», программы непрерывного обучения включают: программы обязательного обучения, обеспечивающие безопасность труда и качество выполнения работ на производстве, программы профессионального развития, в их числе профессиональная подготовка, переподготовка, повышение квалификации, целевые курсы развития профессиональных компетенций, управленческие программы. В настоящее время на площадях Губкинского

\footnotetext{
5 URL: https://www.rosneft.ru/Development/ personnel/staff_development/
} 
университета создается Центр технических компетенций ПАО «НК “Роснефть"» как структурное подразделение компании (фактически корпоративный университет), которое будет реализовывать собственные программы АПО для своих работников.

Системный подход ПАО «Газпром» к развитию персонала в парадигме «образование через всю жизнь» в полной мере отражает утверждённое в январе 2016 г. «Положение о системе непрерывного фирменного профессионального образования персонала ПАО “Газпром". В нём, в частности, сказано, что «непрерььное фирменное профессиональное образование персонала $b$ ПАО "Газиром» является одним из долгосрочных приоритетных направлений Политики управления человеческими ресурсами Общества и осуществляется с целью повышения эффективности и качества труда работников на основе гарантированного обеспечения уровня профессиональных компетенций, соответствующих определённой должности/профессии» (пункт 3.2). Гарантии, о которых идёт речь в Положении, подкрепляются тем, что а) «финансирование расходов на реализацию мероприятий по организации и проведению непрерывного фирменного профессионального образования персонала осуществляется за счёт средств Общества в соответствии со статьёй на подготовку кадров в ежегодно утверждаемых в установленном порядке бюджетах Общества» (пункт 8.10) и б) «средства, предусмотренные Обществом на профессиональное обучение персонала, используются только по прямому назначению» (пункт 8.11).

Свои корпоративные университеты имеют и другие крупные нефтегазовые компании; их деятельность - конкретные и впечатляющие примеры институционального, на корпоративном уровне, обеспечения непрерывного профессионального образования. Анализ содержания реализуемых ими и их подрядчиками (прежде всего - университетами нефтегазового профиля) программ внутрифирменного непрерывного обучения, применяемых образовательных технологий, организации образовательного процесса в целом подтверждает зафиксированную экономистами тесную корреляцию между периодичностью повышения квалификации и профессиональной переподготовкой персонала, с одной стороны, и наукоёмкостью используемых в производстве технологий, с Аругой [17].

Однако при всей своей целостности, полноте и продуманности локальные нормативные документы ведущих отечественных нефтегазовых компаний страны, касающиеся непрерывного образования, подтверждают вышеупомянутые разрывы в системности, скоординированости мероприятий, связанных с переходом на новую нормативную базу в сфере квалификаций. Непрерывное дополнительное образование в них пока ещё практически не сопрягается с профессиональными стандартами - основными, согласно статье 195-1 Трудового кодекса Российской Федерации, государственными нормативными документами в сфере квалификаций, в которых для каждого квалификационного уровня профессий и специальностей прописываются требования к образованию, включая и дополнительное. Нет увязки планирования и финансирования непрерывного обучения персонала с мероприятиями по организации независимой оценки квалификаций работников компаний, что предусмотрено реализуемой в стране (согласно майскому 2012 г. указу Президента Российской Федерации № 597) политикой в сфере квалификаций. Недостаточно прояснён вопрос об опережающем формировании корпуса носителей новых актуальных компетенций, в частности тех тьюторов, наставников, преподавателей, которые должны будут практически обеспечивать дополнительное образование, связанное с новой техникой и новыми технологиями.

Известно, что работодатель хочет, чтобы профессиональной переподготовкой занимались ведущие научно-образовательные центры, имеющие на это не 
только лицензию, но и аккредитованные государством образовательные программы бакалавриата, специалитета, магистратуры. Резон в этом, разумеется, есть: необходима учебно-лабораторная база, современные образовательные технологии, сложившиеся научно-педагогические школы. И Губкинский университет своим собственным опытом вроде бы подтверждает данную точку зрения: в 2006-2013 гг. Институтом проблем развития кадрового потенциала ТЭК университета по заказам нефтегазовых компаний были разработаны и согласованы в Минэнерго России 29 программ профессиональной переподготовки, предусматривавших получение слушателями новых, дополнительных к имеющимся, квалификаций специалистов по актуальным направлениям нефтегазового производства [18]. Из них были лицензированы Минобрнауки России 23 программы. По некоторым из предложенных университетом новых квалификаций впоследствии были разработаны и утверждены Минтруда России профессионахьные стандарты, и эти квалификации включены в национальный реестр.

Этот факт сам по себе свидетельствует о несостоятельности распространённой точки зрения, согласно которой академическому сообществу в разработке профессиональных стандартов должна отводиться роль второго плана. Разработанные программы были востребованы работодателями ТЭК, и казалось вполне очевидным, что Губкинский университет вместе с другими крупными региональными вузами, работающими на отрасль, способны полностью обеспечить потребность компаний в профессиональной переподготовке специалистов нефтегазового профиля. Однако не секрет, что в сфере нефтегазового сервиса, - а это работы, связанные с сейсмикой, бурением горизонтальных скважин и бурением скважин на шельфе, гидроразрывами продуктивных пластов и в целом добычей трудноизвлекаемых запасов углеводородов, - до недавнего времени доминировали зарубежные подрядчики, и, к сожалению, своих научнопедагогических работников, обладающих необходимыми компетенциями Аля обучения российских специалистов по соответствующим программам $А П О$, у нас буквально единицы. По этой причине при реализации программ профессиональной переподготовки, связанных с бурением скважин и добычей углеводородов на шельфе, наш университет активно привлекал к учебному процессу ведущих специалистов из бизнеса и решал сложнейшие вопросы организации стажировок не только обучающихся по программам АПО по технологии дуального обучения [19; 20], но и своих преподавателей в тех зарубежных компаниях, которые ведут эти работы и применяют современное роботизированное буровое оборудование, технологии подводной добычи нефти и газа.

Следует заметить, что в ряде нефтегазовых компаний успешно реализуются специальные программы подготовки собственных преподавателей (тьюторов, тренеров) для своих корпоративных университетов ${ }^{6}$. В связи с этим представляется, что никак не следует исключать из числа возможных провайдеров в области профессиональной переподготовки корпоративные институты и университеты отрасли. К примеру, в текущем году корпоративный институт ПАО «Газпром» реализует 11 программ профессиональной переподготовки; вне всякого сомнения, эти программы успешно пройдут профессионально-общественную аккредитацию совета по профессиональным компетенциям в нефтегазовом комплексе (СПК НГК).

\section{Что такое «новая профессия»?}

Продолжая тему корпоративной и отраслевой политики в сфере непрерывного

${ }^{6}$ URL: http://hr-media.ru/wp-content/uploads/2016/01/Vnutrennee-trenerstvo_Gazprom_ neft.pdf 
образования, необходимо отметить, что у работодателей нет полной ясности в вопросах обретения новыми видами деятельности, новыми профессиями и специальностями статуса таковых. Последнее принципиально важно Аля понимания сущности опережающего непрерывного образования, планирования его содержания и конкретных форм. Риск начинать разработку программ профессиональной переподготовки, ориентированных на новый вид профессиональной деятельности, состоит в том, что организовывать обучение по ним возможно лишь после установления этого статуса на государственном уровне, а значит, выполнения многочисленных бюрократических процедур, согласований и проч., а потому такое обучение будет уже не опережающим, а запаздывающим.

Рассмотрим основания, по которым некий вид трудовой деятельности может официально объявляться новой профессией (специальностью, квалификацией). Федеральным законом «Об образовании в Российской Федерации» определено, что программа повышения квалификации направлена на совершенствование и (или) получение новой компетенции, необходимой для профессиональной деятельности, и (или) повышение профессионального уровня в рамках имеющейся квалификации, а программа профессиональной переподготовки - на получение компетенции, необходимой для выполнения нового вида профессиональной деятельности, приобретение новой квалификачии.

Ао 2013 г. в стране существовала норма ${ }^{7}$, согласно которой:

- нормативный срок прохождения профессиональной переподготовки для выполнения гражданскими служащими нового

\footnotetext{
7 «Государственные требования к профессиональной переподготовке, повышению квалификации и стажировке государственных гражданских служащих», утверждены Постановлением Правительства Российской Федерации от 6 мая 2008 г. № 362.
}

вида профессиональной деятельности должен составлять более 500 аудиторных часов;

- нормативный срок прохождения профессиональной переподготовки для получения гражданскими служащими дополнительной квалификации должен составлять более 1000 часов;

- при освоении программы профессиональной переподготовки гражданскому служащему в качестве её разделов могут быть зачтены программы повышения квалификации (стажировки), освоение которых подтверждено документами государственного образца, полученными не позднее трёх лет до начала обучения по соответствующей программе профессиональной переподготовки;

- освоение гражданскими служащими образовательных программ профессиональной переподготовки завершается обязательной государственной итоговой аттестацией, предусматривающей выпускную квалификационную (аттестационную) работу и экзамен, и по результатам проведения обязательной государственной итоговой аттестации выдаются следующие документы государственного образца:

а) диплом о профессиональной переподготовке - лицам, прошедшим обучение по программе объёмом более 500 аудиторных часов;

б) диплом о дополнительном (к высшему) образовании - лицам, прошедшим обучение по дополнительной профессиональной образовательной программе для получения дополнительной квалификации объёмом более 1000 часов;

- диплом о дополнительном (к высшему) образовании даёт гражданскому служащему право претендовать на замещение должностей гражданской службы, квалификационными требованиями по которым предусмотрено наличие высшего профессионального образования соответствующего профиля.

Федеральный закон № 273-Ф3 упразднил чёткую дифференциацию программ профессиональной переподготовки по часам, 
Фрагмент учебного плана подготовки инженеров по специальности

21.05.06 «Нефтегазовые техника и технологии»

\begin{tabular}{|l|l|l|}
\hline \multicolumn{2}{|c|}{ Структура программы специалиста } & \multicolumn{1}{c|}{$\begin{array}{c}\text { Объём программы } \\
\text { специалиста в 3.е. }\end{array}$} \\
\hline \multirow{3}{*}{ Блок $\mathbf{1}$} & Аисциплины (модули) & $279-291$ \\
\cline { 2 - 3 } & Базовая часть & $189-201$ \\
& В том числе дисциплины (модули) специализации & $39-60$ \\
\cline { 2 - 3 } & Вариативная часть & $90-102$ \\
\hline \multirow{5}{*}{ Блок 2} & Практика, в том числе научно-исследовательская работа (НИР) & $32-42$ \\
\cline { 2 - 3 } & Базовая часть & $15-18$ \\
\cline { 2 - 3 } Блок 3 & Вариативная часть & $15-24$ \\
\hline & Государственная итоговая аттестация & $6-9$ \\
\hline & Базовая часть & $6-9$ \\
\hline & Объём программы специалиста & 330 \\
\hline
\end{tabular}

отменил необходимость утверждения и лицензирования их в органах государственной власти, заменил государственные дипломы об успешном освоении этих программ на дипломы образовательных учреждений установленного образца. Однако он не изменил смысла профессиональной переподготовки как таковой: хотите заниматься новым видом инженерной деятельности, освоить новую специализацию, хотите приобрести новую квалификацию - для этого вам не обязательно получать второе высшее (если вы имеете высшее техническое образование или получаете его в вузе), достаточно пройти профессиональную переподготовку по нужной вам программе в требуемом объёме. То же относится и к лицам со средним специальным образованием. При этом, что особенно важно, программа профессиональной переподготовки может реализовываться в виде последовательности тематически связанных модульных программ повышения квалификации.

Из всего этого следует, что некая трудовая функция или их совокупность в определённом виде трудовой деятельности, меняюшаяся в силу изменения средсть, состава u последовательности трудовьх действии, может тогда потребовать введения новой профессии, квалификачии, спечиальности, иначе говоря, может быть соответствуюшим образом конституирована (внесена в государственный/начиональньй реестр и описана в соответствуюшем профессиональном стандарте), когда требует для своего исполнения такого объёма новьх знании, новьх умений, новьх навыков, для овладения которьми необходимо обучить работника, имеюшего квалификачию в соответствующем виде деятельности (или смежном сни) по программе профессиональной переподготовки, а не имеюшего - по программе новой спечиализачии/профилизачии в рамках образовательной программь среднего/выстего профессионального образования. В подтверждение этого вывода приведём фрагмент учебного плана подготовки инженеров по специальности 21.05.06 «Нефтегазовые техника и технологии» (Табл. 1). Мы видим, что объём дисциплин специализации составляет от 39 до 60 зачётных единиц. В календарном измерении это соответствует одному-двум традиционным вузовским семестрам. А таковыми по объёму учебного контента и продолжительности как раз и являются программы профессиональной переподготовки.

Опираясь на утверждённую Правительством РФ методологию и уже сложившуюся практику разработки профессиональных стандартов, можно также утверждать следующее: новая профессия/специальность или квалификация в нефтегазовой отрасли, как и в любой другой, имеет право быть при- 
знана в качестве таковой, если она требует разработки соответствующего нового профессионального стандарта.

Обязательным, с нашей точки зрения, требованием к указанным программам является их аккредитованность отраслевыми советами по профессиональным квалификациям (СПК). Проведение профессионально-общественной аккредитации образовательных программ, включая программы дополнительного образования, входит в число полномочий, которыми наделены СПК согласно действующему законодательству. Поскольку государственных стандартов на программы АПО нет, то СПК становятся тем авторитетным институтом, которые через процедуру профессионально-общественной аккредитации могут официально подтвердить, обеспечивает ли та или иная программа профессиональной переподготовки получение компетенций, необходимых для выполнения новых трудовых функций, которые в совокупности конституируют новую профессию или квалификацию.

\section{Заключение}

Последнее, о чём хотелось бы сказать относительно институционального обеспечения непрерывного образования, - нацеленная на это очередная трансформация университетов. В парадигме непрерывного профессионального образования удельный вес, значимость дополнительного образования в деятельности ведущих инженерных университетов должны и будут возрастать. Соответственно, новизна, востребованность программ дополнительного профессионального образования, их разнообразие, особые технологии обучения, численность контингента обучающихся, его структура, работодатели-партнёры - все эти параметры и характеристики окажутся вровень с теми, на основании которых сегодня составляются рейтинги университетов.

В странах-лидерах инновационного предпринимательства в национальные системы образования успешно встраиваются специализированные, инновационные по структуре, содержанию и технологиям учебные уч- реждения: «университеты без стен», «школы гибкого обучения и т. п. Специализированные институты непрерывного образования появились и в России. В частности, объявлено о создании таких негосударственных университетов в Москве (www.7480040.ru/) и СанктПетербурге (https://vk.com/unospb). В ведении Минздрава России находится Российская академия непрерывного медицинского образования. Но основной тренд - это создание подобных структур в государственных университетах страны на базе центров АПО. В качестве примера сошлёмся на Институты непрерывного образования Казанского (Приволжского) федерального университета, Астраханского, Башкирского, Вятского, Псковского государственных университетов.

Отдельно как о ярком примере инновационного университета непрерывного образования необходимо сказать о реализуемом в нашей стране в рамках Национальной технологической инициативы проекте сетевого университета НТИ «20.35». По словам одного из идеологов и авторов его концепции А.Н. Пескова, это «принципиально новый университет без стен, без ректоров, без дипломов (вместо них для каждого выпускника сформируют цифровой профиль компетенций, который отражает его реальные достижения и в определённой степени может служить гарантией его успеха). Аанный проект является попыткой практического воплощения ключевых идей, изложенных в докладе «Будущее образования: глобальная повестка дня», презентованного академическому сообществу в конце 2014 г. [20]. Аейтмотив доклада, как отмечено в аннотации к нему, - переход образования от обучения в начале жизни к обучению всю жизнь, с соответствующим радикальным обновлением глобальной архитектуры образования, эскалацией образовательной инфраструктуры за пределы школьно-вузовской системы и становлением локальных, национальных и глобальных образовательных экосистем.

В Университете НТИ появится новый формат обучения, где необходимые обучаемым 
образовательные модули будут индивидуально, с учётом имеющихся у каждого из них компетенций, собираться в различных учебных заведениях с самыми сильными курсами. Обучение будет проводиться как в очном, так и заочном режиме. Первыми студентами университета НТИ «20.35» станут сотрудники российских технологических компаний, главная цель обучения - повышение их компетенции по выводу новых российских продуктов на мировой рынок. Со временем доступ к сетевому университету сможет получить любой желающий, оплатив свое обучение.

\section{\итература}

1. Кинелев В.Г. Образование и цивилизация // Информационное общество.1996. Вып. 3. С. 3-13.

2. Щедровичкий П.Г. Очерки по философии образования. М.: Эксперимент, 1993. 154 с.

3. Колесникова И.А. Концептосфера непрерывного образования: логика и методология изучения // Непрерывное образование в России: XXI век. 2016. Вып. № 3 (15). С. 124-140.

4. Аелор Ж. Образование: сокрытое сокровище. Аоклад Международной комиссии по образованию для ХХІ века. Изд-во ЮНЕСКО, 1996. 46 с. (Аелор Ж. Образование: сокрытое сокровище // Университетская книга. 1997. № 4).

5. Салихова М.М. Европейская модель непрерывного образования - образования длиною в жизнь (Lifelong Learning) // Современное дополнительное педагогическое образование. 2016. № 4. C. 116-121.

6. Похолков Ю.П., Пальянов М.П., Пахомова E.A. Непрерывное техническое образование и рыночные отношения // Профессиональное образование в России и за рубежом. 2015. № 6. C. $25-33$.

7. СженоВ Е.С. О разработке концепции непрерывного образования: основные принципы // Высшее образование в России. 2011. № 2. С. 93-98.

8. Вербиикий А.А. О категориальном аппарате теории контекстного образования // Высшее образование в России. 2017. № 6. С. 57-67.

9. Барбер М., Аоннелли К., Ризви С. Накануне схода лавины. Высшее образование и грядущая революция // Вопросы образования. 2013. № 3. C.152-231.

10. Новиков А.М. Методология образования. М.: Эгвес, 2002. 320 с.
11. Тарасенко Ф.П. Прикладной системный анализ: Учебник. Томск. ИзА-во Томского ун-та, 2004. $186 \mathrm{c}$.

12. Краснова Г.А., Можаева Г.В., Полушкина E.A. Развитие непрерывного профессионального образования за рубежом. Томск: Изд. дом Томского гос. ун-та, 2017. 238 с.

13. Атлас новых профессий. Альманах перспективных отраслей и профессий на ближайшие 15-20 лет. URL: atlas100.ru/upload/pdf_files/ atlas.pdf

14. Аимачко E.E. Человеческий капитал в современной экономике - некоторые теоретические аспекты. Новосибирск: Институт экономики и OOП CO PAH. URL: www.econom.nsc. $\mathrm{ru} /$ ieie/SMU/conference/articles/ Иимачко.doc

15. Шейнбаум B.C. Компетенция «умение работать в команде» и её развитие с использованием технологии междисциплинарного обучения в виртуальной производственной среде // Высшее образование сегодня. 2018. № 2. С. 2-8.

16. Аоргина Н.Н., Мартынов В.Г., Шейнбаум B.C. Теория производства полуфабрикатов и её приложение к высшему и дополнительному профессиональному образованию // Аополнительное профессиональное образование. 2004. № 4(8). C. 32-34.

17. Щекин Г.В. Теория и практика управления персоналом. К.: МАУП, 2003. 280 с.

18. Бородин А.И., Сорочайкин А.Н., Шаш Н.Н. Человеческий капитал компании: проблемы идентификации // Основы экономики, управления и права. 2017. №4 (10). С. 103-108.

19. Аавров В.Н. Человеческий капитал как исходная предпосылка и стратегический фактор конкурентоспособности фирмы // Вестник Уральского института экономики, управления и права. 2008. № 4(5). С. 64-75.

20. Шейнбаум B.С., Зиганшина В.С. Ауальное обучение в системе профпереподготовки лучшая технология превращения бакалавра в реального специалиста-инженера // Ауальное профессиональное образование в стране и мире. 2014. №. 6-7. С. 65-68.

21. Аукша П.О., Песков А.Н. Будущее образования: глобальная повестка дня. URL: https://asi.ru/news/25293/

Статья поступила в редакиию 20.07.18

С доработки 17.08.18

Принята к публикачии 10.09.18 


\section{Institutional Support of Continuing Engineering Education}

OlgaV.Budzinskaya - Cand. Sci. (Economics), Assoc. Prof., e-mail: budzinskaya@bk.ru Viktor S. Sheinbaum - Cand. Sci. (Engineering), Prof., e-mail:shvs@gubkin.ru

Gubkin Russian State University of Oil and Gas (National Research University), Moscow, Russia Address: 65, Leninskiy prosp., Moscow, 119991, Russian Federation

Abstract. The article raises the issue of the need to fix in professional standards, which are the main normative documents in the field of qualifications, the requirements concerning the mandatory continuity of professional competencies of employees, including through the institution of additional professional education. The authors propose possible options for introducing these requirements without changing the established format of professional standards. The article substantiates the leading role of research and design universities as the system-forming structures in the knowledge industry in the formation of qualification requirements for new areas and types of professional activity, the necessity to develop and implement professional retraining programs for specialists before they officially acquire the corresponding status and the professional standards will be developed and approved for them.

Keywords: continuing professional education, professional standards, digitalization, additional vocational education, branch councils on professional qualifications

Cite as: Budzinskaya O.V., Sheinbaum V.S. (2018). [Institutional Support of Continuing Engineering Education]. Vysshee obrazovanie v Rossii = Higher Education in Russia. Vol. 27. No. 10, pp. 30-46. (In Russ., abstract in Eng.)

DOI: https://doi.org/10.31992/0869-3617-2018-27-10-30-46

\section{References}

1. Kinelev, V.G. (1996). [Education and Civilization]. Informatsionnoe obshchectvo [Information Society]. No. 3, pp. 3-13. (In Russ.)

2. Shchedrovitsky, P.G. (1993). Ocherki po filosofii obrazovaniya [Essays on the Philosophy of Education]. Moscow: Experiment Publ. 154 p. (In Russ.)

3. Kolesnikova, I.A. (2016). [Conceptual Sphere of Continuing Education: The Logic and Methodology of Studying]. Nepreryvnoe obrazovanie v Rossii: XXI vek [Lifelong Learning: XXI Century]. No. 3(15), pp. 124-140. (In Russ., abstract in Eng.)

4. Delors, J. (1996). Learning: The Treasure Within. Report to UNESCO of the International Commission on Education for the Twenty-first Century. UNESCO Publishing.

5. Salikhova, M.M. (2016). [European Model of Lifelong Education (Life long Learning)]. Sovremennoe dopolnitelnoe pedagogicheskoe obrazovanie [Modern Additional Pedagogical Education]. No. 4, pp. 116-121. (In Russ., abstract in Eng.)

6. Pokholkov, Yu.P., Pal'yanov, M.P, Pakhomova, E.A et al. (2015). [Continuing Technical Education and Market Relations]. Professionalnoe obrazovanie $v$ Rossii $i$ za rubezhom [Vocational Education in Russia and Abroad]. No. 6, pp. 25-33 (In Russ., abstract in Eng.)

7. Szhenov, E.S. (2011). [On the Development of the Concept of Continuous Education: The Basic Principles]. Vysshee obrazovanie $v$ Rossii = Higher Education in Russia. No. 2, pp. 93-98. (In Russ., abstract in Eng.)

8. Verbitsky, AA, (2017) [On the Categorical Apparatus of the Theory of Context Formation]. Vysshee obrazovanie $v$ Rossii = Higher Education in Russia. No. 6, pp. 57-67. (In Russ., abstract in Eng.) 
9. Barber, M., Donnelly, C., Rizvi, S. (2013) [On the Eve of the Avalanche. Higher Education and the Coming Revolution]. Voprosy obrazovaniya [Issues of Education]. No. 3, pp.152-231. (In Russ.)

10. Novikov, A.M. (2002). Metodologiya obrazovaniya [Methodology of Education]. Moscow: Egves Publ., 320 p. (In Russ.)

11. Tarasenko, F.P. (2004). Prikladnoi sistemnyi analiz: Uchebnik [Applied Systems Analysis: A Textbook]. Tomsk: Tomsk Univ. Publ. 186 p. (In Russ.)

12. Krasnova, G.A., Mozhaeva, G.V., Polushkina, E.A. (2017). Razvitie nepreryvnogo professional' nogo obrazovaniya za rubezhom [Development of Continuing Professional Education Abroad]. Tomsk: Tomsk State Univ. Publ. 238 p. (In Russ.)

13. ASI. Atlas of New Professions for the Next 15-20 Years. Available at: www.atlas100.ru/upload/ pdf_files/atlas.pdf (In Russ.)

14. Limachko, E.E. [Human Capital in the Modern Economy - Some Theoretical Aspects]. Novosibirsk: Institute of Economics and Environmental Protection of the Siberian Branch of the Russian Academy of Sciences. Available at: www.econom.nsc.ru/ieie/SMU/conference/articles/ Limachko.doc (In Russ.)

15. Sheinbaum, V.S. (2018). [Competence "Teamwork Ability " and its Development Using the Technology of Interdisciplinary Training in a Virtual Production Environment]. Vysshee obrazovanie Segodnya [Higher Education Today]. No. 2, pp. 2-8. (In Russ., abstract in Eng.)

16. Lorgina, N.N., Martynov, V.G., Sheinbaum, V.S. (2004). [The Theory of Production of Semifinished Products and its Application to Higher and Additional Vocational Education]. Dopolnitelnoe professionalnoe obrazovanie [Additional Vocational Education]. No. 4(8), pp. 32-34. (In Russ.)

17. Shchekin, G.V. (2003). Teoria i praktika upravleniya personalom [Theory and Practice of Personnel Management]. Kiev: MAUP Publ. 280 p. (In Russ.)

18. Borodin, A.I., Sorochaykin, A.N., Shash, N.N. (2013). [Human Capital of the Company: Identification Problems]. Osnovy ekonomiki, upravlenia i prava [Fundamentals of Economics, Management and Law]. No. 4 (10), p. 103-108. (In Russ.)

19. Lavrov, V.N. (2008). [Human Capital as an Initial Prerequisite and Strategic Factor of the Firm's Competitiveness].Vestnik uralskogo instituta ekonomiki, upravlenia $i$ prava [Bulletin of the Ural Institute of Economics, Management and Law]. No. 4 (5), pp. 64-75. (In Russ.)

20. Sheinbaum, V.S., Ziganshina, V.S. (2014). [Dual Training in the System of Professional Retraining is the Best Technology of Turning a Bachelor into a Real Specialist Engineer]. Dualnoe professionalnoe obuchenie v strane i mire [Dual Professional Education in the Country and in the World]. No. 6-7, pp. 65-68. (In Russ.)

21. Luksha, P.O, Peskov, D.N. Budushchee obrazovaniya: globalnaya povestka dnya [The Future of Education: The Global Agenda]. Available at: https://asi.ru/news/25293/ (In Russ.)

The paper was submitted 20.07.18

Received after reworking 17.08 .18

Accepted for publication 10.09.18 